University of Wollongong

Research Online

Faculty of Social Sciences - Papers (Archive) Faculty of Arts, Social Sciences \& Humanities

2013

Vegetables containing phytochemicals with potential anti-obesity

properties: a review

David J. Williams

Agri-Science Queensland

David Edwards

Agri-Science Queensland

Ingrid Hamernig

University of Queensland

Le Jian

Department of Health, Western Australia

Anthony P. James

Curtin University

See next page for additional authors

Follow this and additional works at: https://ro.uow.edu.au/sspapers

Part of the Education Commons, and the Social and Behavioral Sciences Commons

Research Online is the open access institutional repository for the University of Wollongong. For further information contact the UOW Library: research-pubs@uow.edu.au 


\title{
Vegetables containing phytochemicals with potential anti-obesity properties: a review
}

\begin{abstract}
The incidence of obesity is rising worldwide at an alarming rate and is becoming a major public health concern with incalculable social and economic costs. Studies have exposed the relationship between the adiposity, inflammation and the development of other metabolic disorders, so dietary factors that influence some or all of these are of interest. Dietary phytochemicals appear to be able to target different stages of the adipocyte (fat cell) lifecycle. For example, several classes of polyphenols have been implicated in suppressing the growth of adipose tissue through modifying the adipocyte lifecycle. Many dietary phytochemicals also have strong anti-inflammatory activity, but the amount present in plants varies and may be affected by processing. In this review we summarise the likely mechanisms of action of plant phytochemicals. We highlight the major vegetable sources of polyphenols, including those with possible synergistic attributes, discuss the variation in polyphenol levels and their distribution in cultivars and outline the effects of food processing. The identification and characterisation of the anti-obesogenic properties of phytochemicals in vegetables, as well as an appreciation of the effect of cooking on phytochemical content provide significant new information supporting dietary guidelines that encourage vegetable consumption for the prevention and management of lifestyle related disease.
\end{abstract}

\section{Keywords}

obesity, properties, vegetables, containing, phytochemicals, potential, anti, review

\section{Disciplines}

Education | Social and Behavioral Sciences

\section{Publication Details}

Williams, D. J., Edwards, D., Hamernigb, I., Jian, L., James, A. P., Johnson, S. K. \& Tapsell, L. C. (2013). Vegetables containing phytochemicals with potential anti-obesity properties: a review. Food Research International, 52 (1), 323-333.

\section{Authors}

David J. Williams, David Edwards, Ingrid Hamernig, Le Jian, Anthony P. James, Stuart Keith Dr Stuart Keith Johnson, and Linda Tapsell 
1 Review

3 Vegetables containing phytochemicals with potential anti-

4 obesity properties: a review

5 David J. Williams ${ }^{{ }^{*}}$, David Edwards ${ }^{a}$, Ingrid Hamernig ${ }^{b}$, Le Jian ${ }^{c}$,

6 Anthony P. James ${ }^{d}$, Stuart K. Johnson ${ }^{d}$, Linda C Tapsell

7 a Agri-Science Queensland, Department of Agriculture, Fisheries and Forestry

8 (DAFF), PO Box 156, Archerfield BC, Queensland, 4108, Australia

$9 b^{b}$ Institute of Molecular Biosciences, The University of Queensland, St. Lucia,

10 Queensland, 4072, Australia

$11{ }^{c}$ Department of Health, 189 Royal Street, East Perth, Western Australia, 6004,

12 Australia

$13{ }^{d}$ School of Public Health, Curtin Health Innovation Research Institute, Curtin

14 University, GPO Box U1987, Perth, Western Australia, 6845, Australia

$15{ }^{e}$ Smart Foods Centre, School of Health Sciences, University of Wollongong NSW

162522 , Australia

* Corresponding author. Tel.: +61 732766041 fax: +61 732166591 E-mail

21 address: david.williams@daff.qld.gov.au 


\section{ABSTRACT}

The incidence of obesity is rising worldwide at an alarming rate and is becoming a major public health concern with incalculable social and economic costs. Studies have exposed the relationship between the adiposity, inflammation and the development of other metabolic disorders, so dietary factors that influence some or all of these are of interest. Dietary phytochemicals appear to be able to target different stages of the adipocyte (fat cell) lifecycle. For example, several classes of polyphenols have been implicated in suppressing the growth of adipose tissue through modifying the adipocyte lifecycle. Many dietary phytochemicals also have strong anti-inflammatory activity, but the amount present in plants varies and may be affected by processing. In this review we summarise the likely mechanisms of action of plant phytochemicals. We highlight the major vegetable sources of polyphenols, including those with possible synergistic attributes, discuss the variation in polyphenol levels and their distribution in cultivars and outline the effects of food processing. The identification and characterisation of the anti-obesogenic properties of phytochemicals in vegetables, as well as an appreciation of the effect of cooking on phytochemical content provides significant new information supporting dietary guidelines that encourage vegetable consumption for the prevention and management of lifestyle related disease. 
49 Keywords:

50 Adipocyte lifecycle

51 Anti-obesity phytochemicals

52 Polyphenols

53 Carotenoids

54 Organosulphurs

$55 \quad$ Cooking 


\section{Introduction}

In 1998 obesity was defined as a "phenotypic manifestation of abnormal or excessive fat accumulation that alters health and increases mortality" (World Health Organisation, 1998). The WHO report stated that obesity had reached epidemic proportions worldwide. Since then its incidence has continued to rise at an alarming rate in both developed and developing countries and is becoming a major public health concern with incalculable social costs (Popkin, Kim, Rusev, Du, \& Zizza, 2006; Popkin, 2009). There is a strong association between obesity and chronic diseases such as diabetes, cardiovascular diseases, hypertension, osteoarthritis, some cancers and inflammation-based pathologies which suggests that the obese are likely to have a disproportionate use of the health care system (Marinou, Tousoulis, Antonopoulos, \& Stefanadi, 2010; Piper, 2011; Singla, Bardoloi, \& Parkash, 2010). In order to maintain quality of life for the population and decrease the economic burden on the health system, more powerful dietary strategies to help reduce this cluster of diseases are urgently required.

While the strategy of reducing dietary fat content combined with increased physical activity has been shown to be effective in preventing obesity (Astrup, 2001; World Health Organisation, 2007), numerous studies have shown that this simple message is being ignored and alternative strategies are being sought (Kruger, Galuska, Serdula, \& Jones, 2004; Stern et al., 1995; Wadden, 1993). Obesity is characterised at the cellular level by an increase in the number and size of adipocytes (fat storage cells) that have differentiated from pre-adipocytes in the adipose tissue (Furuyashiki et al., 2004). This transition from undifferentiated pre- 
83 adipocytes into mature adipocytes constitutes the adipocyte life cycle, and hence

84 treatments that regulate both the size and number of adipocytes may provide a valuable adjunct to reduced dietary energy in combating obesity. The relationship between adiposity and inflammation is also being gradually unravelled with the recognition that adipocytes also produce inflammatory cytokines, suggesting that obesity induces an inflammatory state which may lead to further disease progression (Grundy, 2012).

With this in mind considerable interest has been aroused worldwide in the potential of dietary phytochemicals to help counteract obesity (Park \& Kim, 2011; Rayalam, Della-Fera, \& Baile, 2008; Santos, Rogero, \& Bastos, 2010). Cell culture and animal model studies have indicated the anti-obesity effects occur through modification of the adipocyte life cycle. Polyphenols are a class of phytochemicals that are likely candidates as anti-obesity agents as several studies have suggested they can modulate the adipocyte life cycle (Rayalam et al., 2008; Yun, 2010). The strongest evidence is for this effect comes from: phenolic acid derivatives such as chlorogenic acid (Camire, Kubow, \& Donnelly, 2009, Pan Lai, \& Ho, 2010); the flavonols e.g. quercetin (Yun, 2010); and flavones such as luteolin (Rayalam et al., 2008). These classes of polyphenols (Figure 1) are widely distributed in plants and therefore are consumed regularly as part of the human diet.

(1)

Anti-obesity mechanisms of phytochemicals appear to involve mediation of complex and interconnected cell signalling pathways, therefore the combination of multiple phytochemicals may give rise to synergistic and enhanced anti-obesity effects. Synergistic interactions with combinations of phytochemicals have previously 


.

been investigated for the treatment of some cancers (Chan, Fong, Soprano, Holmes, \& Heverling, 2003; Hermalswarya \& Doble, 2006; Suganuma et al., 1999). However, such synergistic interactions among dietary bioactives acting on adipocytes have received only limited attention (Adams \& Cory, 1998; Yang, Della-Fera, Hausman, \& Baile, 2007). So far these studies have been encouraging with results indicating an enhanced induction of apoptosis and suppression of adipogenesis by phytochemcals used in combination. Phytochemical combinations that included polyphenols such as stilbene, resveratrol, genistein and naringenin have proven the most effective (Baile et al., 2011; Nelson-Dooley, Della-Fera, Hamrick, \& Baile, 2005). Results from such studies suggest that anti-obesity effects could be achieved by consuming lower levels of phytochemicals but in specific combinations.

anti-obesity properties, with the types and levels varying markedly between species and even cultivar (Nuutila, Puupponen-Pimia, Aarni, \& Oksman-Caldentey, 2003; Singh, Upadhyay, Prasad, Bahadur, \& Rai, 2007). In addition climatic, agronomic and harvest conditions also significantly influence the levels of these phytochemicals in vegetables (Naczk \& Shahidi, 2006; Tiwari \& Cummins, 2011).

Post-harvest operations, including food processing have a major influence on the levels of phytochemicals in vegetables and vegetable products. Conventional (thermal), non-thermal (e.g. high pressure, ultrasound, irradiation), domestic (e.g. washing, peeling, cutting) and industrial (canning, drying) processing are widely reported to degrade phytochemicals (Rawson, Koidis, Rai, Tuohy, \& Brunton, 2010; Volden, Bengtsson, \& Wicklund, 2009). Heat treatment is the most common method 
133 for processing vegetables because of its inactivation of pathogenic and spoilage

134 microorganisms and endogenous enzymes leading to improved quality and shelf-life

135 (Rawson et al., 2011). To retain phytochemicals during the various cooking

136 treatments on offer, the food processor must optimise all steps in order to restrict

137 their degradation.

138

With this backdrop, the aims of this review are to summarise the proposed mechanisms of action of phytochemicals on obesity related pathways, highlight the vegetable sources of phytochemicals; and discuss the influence of different cultivars and distribution within the vegetable source as well as the impact of cooking on the

143 levels of these phytochemicals.

\section{Mechanisms of action of phytochemicals on adiposity}

The plausible mechanisms of action of certain vegetable phytochemicals include: (a) reducing adipose tissue mass by inhibiting the proliferation of precursor

149 cells; (b) increasing the rate of apoptosis during the adipocyte lifecycle (Rayalam et al., 2008; Yun, 2010) and (c) the inhibition of dietary triglyceride absorption via reduction in pancreatic lipase formation (Birari \& Bhutani, 2007). Obesity has been associated with a chronic inflammatory status (Pan et al. 2010) and the strong antiinflammatory activity may be one of the mechanisms of action for counteracting the negative physiological effect of the obesogenic state.

The development and maintenance of obesity involves many complex molecular mechanisms and interconnected cell signalling pathways and to discuss recent advances in this topic is well beyond the scope of this review. Therefore the 
current review is restricted to a summary of proposed mechanisms of action of the major vegetable phytochemicals.

\subsection{Polyphenols}

Polyphenols are a class of phytochemicals widespread in vegetables that have demonstrated one or more potential anti-obesity effects. Dietary polyphenols may suppress growth of adipose tissue by modulating adipocyte metabolism (Badimon, Vilahur, \& Padro, 2010; Mulvihill \& Huff, 2010). Unfortunately to date, the effects of polyphenols on human adipocytes have not been studied systematically; most studies having been conducted on murine cell lines such as 3T3-L1 and in the tissues of laboratory animals (Hsu \& Yen, 2006; Morikawa, Ikeda, Nonaka, \& Suzuki, 2007).

Polyphenols, including their functional derivatives, esters and glycosides, have one or more phenol groups with one hydroxyl - substituted aromatic ring (Dey \& Harborne, 1989). According to their structure and the type and number of structural elements binding to the rings, polyphenols are grouped into different classes (Figure 1). The classes of polyphenols for which there is most evidence of potential anti-obesity properties are: (1) the simple phenolic acids such as chlorogenic, coumaric, gallic and caffeic acids and (2) the flavonoid sub-classes, flavonols e.g. quercetin, kaempferol, myricetin and isorhamnetin and the flavones e.g. luteolin and apigenin.

\subsubsection{Phenolic acids: chlorogenic acid and related compounds}


Naturally occurring phenolic acids contain two distinguishing constitutive carbon frameworks: hydroxycinnamic and hydroxybenzoic structures. Although the basic skeleton remains the same, the numbers and positions of the hydroxyl groups on the aromatic ring create the variety (Figure 1). Common hydroxycinnamic acid derivatives are coumaric, caffeic and ferulic acids which frequently occur in foods as simple esters with quinic acid or glucose. The most widely occurring of these is chlorogenic acid. Unlike hydroxycinnamates, hydroxybenzoic acid derivatives are mainly present as glycosides. The most common forms in plant foods are $p$ hydroxybenzoic and vanillic acids (Herrmann, 1989).

Hsu and Yen (2006) investigated the inhibitory effect of dietary phenolic acids on mouse pre-adipocytes. Chlorogenic and coumaric acids caused significant inhibition of cell growth as well as enhancing apoptosis. Gallic acid while not affecting the adipocyte cell cycle did increase the number of apoptotic cells. A recent study (Son, Rico, Nam, \& Kang, 2010) evaluated the effects of feeding ferulic acid on lipid metabolism of mice. This dietary phenolic acid suppressed the weight gain due to the high fat diet and inhibited fatty acid biosynthesis.

\subsubsection{Flavonoids: flavonols, flavones and anthocyanins}

Flavonoids are a class of polyphenols that are widely distributed in vegetables and can be further differentiated into sub-classes according to their structure. They share the common skeleton of diphenylpropanes $\left(\mathrm{C}_{6}-\mathrm{C}_{3}-\mathrm{C}_{6}\right)$. The main difference between the two important sub-classes, i.e. the flavonols and the flavones is the 
209 presence of a hydroxyl group at $\mathrm{C}_{3}$ in flavonols (Figure 1 ). They both usually occur in

210 plants as glycosides.

\subsubsection{Flavonols: quercetin and related compounds}

Quercetin is a dietary flavonol found in vegetables, for which there is most evidence for its potential anti-obesity effects. It has been shown to inhibit adipogenesis (Strobel et al., 2005) and to induce apoptosis in mouse pre-adipocytes (Fang et al, 2008; Hsu \& Yen, 2006; Kuppusamy \& Das, 1992). Kaempferol has also exhibited these potential anti-obesity properties but to a lesser extent (Fang, Gao, \&

219 Zhu, 2008). A recent study (Ahn, Lee, Kim, Park, \& Ha, 2008) provided useful insights into the molecular mechanisms by which quercetin influences the regulation of fat cell differentiation and apoptosis.

Park, Yang, and Amabati (2008) exposed human adipocytes to quercetin in combination with the isoflavone, genistein and the stilbene, reservatrol to human adipocytes. The combined treatments caused enhanced inhibition of lipid accumulation in maturing human adipocytes, far greater than the responses to individual compounds.

Several studies have revealed that quercetin provides some protective effects against obesity-related inflammation (Al-Fayez, Cai, Tunstall, Steward, \& Gesher, 2006; Chuang, Martinez, \& Xie, 2010). Quercetin was demonstrated to attenuate markers of inflammation, macrophages and insulin resistance in human adipocytes and reduce circulating markers of inflammation in animal models. 


\subsubsection{Flavones: Iuteolin and apigenin}

236

Park, Kim, and Kim (2009) demonstrated an anti-adipogenic effect of the

flavone, luteolin on murine 3T3-L1 pre-adipocytes mediated through decreased lipid accumulation and inhibition of differentiation. An earlier study (Kuppusamy \& Das, 1992) had shown that the addition of a similar flavone, apigenin induced lipolysis in rat adipocytes.

\subsubsection{Anthocyanins}

Another flavonoid sub-class with potential for anti-obesity-related effects is the anthocyanins, responsible for the red, blue and purple colours in vegetables (Clifford, 2000). In situ, anthocyanins are stabilised by the formation of complexes with other flavonoids and their degradation is prevented by glycosylation and esterification with various organic acids and phenolic acids. In a 2008 study, Tsuda showed that anthocyanins possess significant anti-inflammatory properties in obese adipose tissues.

Another possible anti-obesity mechanism associated with anthocyanins was reported by Sasaki et al. (2007). They observed that cyanidin, the most common anthocyanin in foods, reduced blood glucose levels as well as down regulating inflammatory protein cytokines such as monocyte chemoattractant protein-1 (MCP-1) in the adipose tissue of mice. Recent studies have demonstrated that an increase in 
expression of these inflammatory molecules in adipose tissue contributes to the development of insulin resistance (Kamei et al., 2006; Sartipy \& Loskutoff, 2003).

\subsection{Carotenoids}

Carotenoids, though not polyphenols, but rather a sub-class of terpenoids, have been reported to possess anti-obesity and anti-inflammatory abilities (Gonzalez-Castejon \& Rodriguez-Casado, 2011). Carotenoids are classified into hydrocarbons (carotenes) and their oxygenated derivatives (xanthophylls). They are responsible for the yellow, orange and red colour of many vegetables. $\alpha$-Carotene is one of the most abundant carotenoids in the diet and can be converted in the body to an active form of vitamin A. B-Carotene inhibits inflammatory gene expression in lipolysaccharide-stimulated macrophages. Possible anti-obesity roles for both these carotenes have been postulated based on the finding that the plasma of overweight and obese children had significantly lower levels of $\alpha$-carotene and $ß$-carotene when compared to healthy weight children (Burrows, Warren, Colyvas, Garg, \& Collins, 2009).

\subsection{Organosulphurs}

Several investigations have noted that organosulphur compounds isolated from Allium vegetables have induced apoptosis of human tumour cells (Nishikawa, Yamada, Hattori, Fukada, \& Fujino, 2002; Siegers, Steffen, Robke, \& Pentz, 1999). One of the principal constituents believed largely responsible for these effects is allicin. Allicin is not present as such in the intact vegetable but is produced in the 
283 presence of the enzyme, allinase during cutting or crushing. Allicin is chemically unstable and rapidly breaks down to give the unsaturated disulphide, ajoene.

To evaluate the efficacy of these compounds to induce apoptosis of adipocytes, Elkayam et al. (2003) fed pure allicin to rats with fructose-induced hyperlipidemia, hyperinsulinemia and hypertension. They observed that of the three feeding regimes only those given pure allicin exhibited no weight gain which indicated to the authors that allicin may have benefits in controlling weight in humans. In a similar study, Yang, Della-Fera, Nelson-Dooley, and Baile (2006) noted that the application of pure ajoene induced apoptosis in 3T3-L1 adipoytes. These

293 findings lead them to conclude that ajoene can regulate fat cell numbers through the induction of apoptosis and therefore may be useful as a new therapeutic agent to combat obesity.

Another class of organosulphurs receiving attention as anti-obesity agents are the glucosinolate hydrolysis products (Gonzalez-Castejon \& Rodriguez-Casado, 2011). Glucosinolates are sulphur containing natural plant products found in Brassica vegetables. They occur in the plant in conjunction with the hydrolytic enzyme, myrosinase and in intact tissues, the enzyme is stored separately from the

302 glucosinolates. When tissue damage occurs (food preparation, chewing or pest attack) glucosinolates are hydrolysed by the myrosinases to a range of breakdown products such as isothiocyanates, nitriles, and indoles (Williams, Critchley, Pun, Nottingham, \& O'Hare, 2008). It is these breakdown products that are biologically active most notably the isothiocyanates and indoles and not the precursor

307 glucosinolates. The type of product that is formed depends on $\mathrm{pH}$, structure of 
308 glucosinolate side chain and the presence or absence of supplementary specifier

309 proteins such as epithiospecifier proteins (ESPs) (Williams et al., 2008). The

310 isothiocyanate, sulphoraphane (produced by the action of myrosinase on the

311 glucosinolate, glucoraphanin) has received much attention for its perceived anti-

312 carcinogenic activity and possible anti-obesogenic effects. To date, investigations

313 that aim to evaluate possible anti-obesogenic properties of these compounds have

314 focussed on their anti-inflammatory attributes, particularly the isothiocyanate,

315 sulphoraphane and indole-3-carbinol. Sulphoraphane has been found to decrease

316 the production of inflammatory signalling molecules in cultured macrophages (Heiss,

317 Herhaus, Klimo, Bartsch, \& Gerhauser, 2001). Data is also accumulating that

318 suggests sulphoraphane suppresses the activation of lipopoly-saccharide-induced

319 transcription factors involved in inflammation and cancer (Woo \& Kwon, 2007).

320 Similar to sulphoraphane, a role for indole-3-carbinol in controlling inflammation is

321 emerging as outlined by Cho et al. (2008). Glucosinolate breakdown products have

322 well-known anti-carcinogenesis properties which includes blocking the cell cycle and

323 promoting apoptosis (reviewed in Cartea \& Velasco, 2008). Whether these attributes apply to the adipocyte lifecycle could prove to be an exciting area of future research.

With the exception of this observational study, most of the evidence supporting the effects of dietary phytochemicals on obesity comes from mechanistic studies using cell lines or animal models. This type of research provides help to generate hypotheses for studies in humans and adds to the plausibility of guidance to move towards more plant based diets for the prevention of chronic lifestyle related

331 disease. Indeed, the targeting of several points in the adipocyte lifecycle by dietary 332 phytochemicals has been proposed as a potentially effective obesity treatment 
333 approach (Badimon et al., 2010). Direct evidence of effects from clinical trials is

334 required however, to confirm the anti-obesogenic effects of diets high in 335 phytochemicals.

\section{Major vegetable sources of anti-obesogenic phytochemicals}

To move forward with this research, accurate and reproducible methods for isolating and determining the amounts of these compounds are required. The diverse chemical natures of phytochemical species complicate the extraction and hydrolysis steps required for their determination. Although numerous extraction methods for phytochemcials have been described in the literature, a common feature

344 is that their validation is performed using only one plant material type and for only one specific class of phytochemicals. Likewise, Nuutila, Kammiovirta, and OksmanCaldentey (2002) suggested that the hydrolysis conditions needed to be optimised separately for each plant species under investigation. Some of the discrepancies in the literature between levels of individual polyphenols from the same vegetable source could in part be attributed to the differing extraction and hydrolysis protocols used (Tables 1-3).

\subsection{Vegetable sources of phenolic acids: chlorogenic acid and related compounds}

353

Potato and sweetpotato are rich in chlorogenic acids that constitute up to $90 \%$ of the total phenolic content of these vegetables (Table 1). Tuber size and variety was reported to have little effect on chlorogenic acid content of potatoes, with smaller varieties only showing insignificantly lower values than larger ones 
358 (Friedman, 1997; Table 1). Different sweetpotato cultivars grown under the same

359

360

\subsection{Vegetable sources of flavonols: quercetin and related compounds}

\& Hellstrom, 2007). Carrot also has been reported to have high levels of the phenolic acid, p-hydroxybenzoic acid (Mattila \& Kumpulainen, 2002). Ferracane et al. (2008) isolated significant quantities of chlorogenic acid isomers from globe artichoke with 5-O-caffeoylquinic and 1,5-dicaffeoylquinic acids being the predominant forms. 

Onions, an important crop of the Allium family, contain high amounts of

384

385 quercetin, with levels varying between cultivar but also within the different layers of the onion bulb. Studies on red onions showed the dry skin fraction contained 3 times the level of quercetin than the outer fleshy layer and the inner edible portion (Gennaro et al., 2002; Table 2). The outer layers of onions were shown to contain up to 10 times the levels of quercetin and kaempferol than the inner layers (onion variety not specified), with low levels of myricetin present but only in the inner leaves (Chu, Chang, \& Hsu, 2000). It should be noted that these authors presented the flavonol values on an as-is basis (FW), therefore the drier skin and outer layers give rise to enhanced values when compared to the moist inner layers.

Lettuce (Crozier, Jensen, Lean, \& MacDonald, 1997a), broccoli (El-Gharras, 2009) and curly kale (Olsen, Aaby, \& Borge, 2010) also have high quercetin contents. Kale was also a significant source of kaempferol (Hollman \& Arts, 2000, Olsen et al., 2010). Capsicum also contained appreciable levels of quercetin (Table 2). Sweetpotato leaves are rich in quercetin and myricetin (Chu et al., 2000) (see Table 2). Rutin, a common glycoside of quercetin has been found in large amounts (0.03-0.06\% FW) in asparagus shoots (Wang et al., 2003).

\subsection{Vegetable sources of flavones: Iuteolin and apigenin}

Flavones are much less common than flavonols in vegetables (GonzalezCastejohn \& Rodriguez-Casado, 2011). Natural flavones consist of glycosides of luteolin and apigenin, which are corresponding flavones to the flavonols, quercetin and kaempferol, respectively (Figure 1). The only significant vegetable sources of 
408 flavones identified to date are parsley and celery (Crozier, Lean, MacDonald, \&

409 Black, 1997b; Harnly et al., 2006; Meyer, Bolarinwa, Wolfram, \& Linseisen, 2006;

410 Table 3). Highly variable levels of luteolin and apigenin were found in different

411 varieties of celery (Crozier et al., 1997b). The authors suggested that this variation

412 may have been related to different light regimes during growth or different

413 storage/transport conditions. Celery leaf is a significant source of luteolin and

414 apigenin, while the stalk and heart contain much lower levels (Hollman \& Arts, 2000;

415 Crozier et al., 1997b; Table 3).

416

Relatively high luteolin and apigenin levels have also been reported in globe

artichoke (Azzini et al., 2007) (Table 3). Sun et al. (2007) detected significant amounts of luteolin in capsicum confirming the earlier measurements of Hollman and Arts (2000).

\subsection{Vegetable sources of organosulphurs}

423

Many plants belonging to the Allium group such as garlic, onion, shallot and 425 leek are rich sources of organosulphurs, including allicin, its precursor, allin and other thiosulphinates (Sahu, 2002). Allicin, the main bioactive ingredient is highly unstable and easily breaks down to ajoene, vinyldithins, diallyl trisulphide or other sulphides in air or water (Miron et al., 2002). It is these molecules that are responsible for the characteristic aroma and flavour of Allium vegetables (Sahu, 2002). However this instability makes comparison of allicin content between

431 vegetables difficult with one group of researchers even suggesting that this 432 compound cannot be detected in most biological samples (Itakura et al., 2001). 
433 Using gas chromatography (GC) these authors measured the allicin content

434 (determined as vinyldithin after allicin decomposed in the injection port) of a range of

435

436

437

438

439

440

441

442

443

444

445

446

447

448

449

450

451

452

453

454

455

456

457 vegetables. Allicin was the predominant thiosulpinate constituent in garlic but was absent in the samples of onion and leeks. The erroneous picture of thiosulphinate composition given by GC had been recognised earlier by Block, Naganathan, Putman, and Zhao in 1992. After stating that high performance liquid chromatography (HPLC) offered a more reliable measure of thiosulphinates in plants they identified and quantified these molecules in a broad range of vegetables. They found that garlic possessed by far the highest levels followed by the onion varieties. The major thiosulphinate found in the garlic samples was allicin present to the extent of $0.3 \% \mathrm{FW}$. These findings were in direct contrast to those given by Cheng (2006). Also using HPLC this study found that onion possessed the highest allicin content with $0.168 \mathrm{mg} / \mathrm{g}$ DW followed by garlic $(0.051 \mathrm{mg} / \mathrm{g} \mathrm{DW})$ with chives and leeks having no detectable amounts.

7

From a dietary point of view glucosinates are restricted to plants of the Brassica species. Several of these species are widely consumed by humans as cooked or salad vegetables such as cabbage, Brussels sprouts, cauliflower, broccoli, turnip, radish and watercress or condiments including horseradish and white mustard. Actually, more than 130 glucosinolates have been identified; however most species contain a limited number (generally less than twelve) (Halkier \& Gershenzon, 2006). Previous studies have found that the composition and content of glucosinolates vary widely, not just between the various Brassica species but also the different developmental stages and tissues within a given species (Porter, Morton, Kiddle, Doughty, \& Wallsgrove, 1991; Koroleva et al., 2000). Broccoli (both 
458 the sprouts and mature vegetables) are rich-sources of glucoraphanin (Fahey,

459 Zhang, \& Talalay, 1997). However it is worth noting that several studies have

460 reported that broccoli possesses epithiospecifier proteins (ESPs) particularly in the 461 early stages of plant development (Matusheski, Juvik, \& Jeffery, 2004; Williams et 462 al., 2008). These ESPs redirect the glucosinolate breakdown to the non-bioactive 463 nitriles at the expense of isothiocyanate formation (reviewed by Kissen, Rossiter, \& 464 Bones, 2009).

465

\subsection{Vegetable sources of multiple phytochemicals}

467

Complex mechanisms are involved in regulating adipose tissue development by dietary phytochemicals, it follows that exposure of adipocytes to multiple vegetable phytochemicals found in a high vegetable diet could result in enhanced or even synergistic effects. There are several vegetables that contain appreciable

472 levels of a range of these compounds. The presence of two natural plant pigments 473 with anti-obesity mechanisms is also noted in these same vegetables, and recent studies (reviewed by Tiwari \& Cummins, 2011) have indicated that dark coloured cultivars of vegetables possess higher levels of phytochemicals when compared to light coloured varieties.

\subsubsection{Orange-fleshed sweetpotato}

479

The commonly consumed edible portions of sweetpotato contain higher levels

481 of chlorogenic acids than most potato varieties (Table 1). Chlorogenic acids were 482 approximately 2-fold higher in orange-fleshed varieties compared to those with 
483 cream-coloured flesh (Rautenbach, Faber, Laurie, \& Laurie, 2010). Padda and Picha

484 (2008) further noted that total chlorogenic acid content of the purple-fleshed variety contained the highest levels, while one white-fleshed variety had nearly twice the content of the other white- and orange-fleshed varieties (Table 1).

487

Some sweetpotato varieties have also been reported to be rich in ß-carotene;

particularly those with dark yellow or orange flesh (Rautenbach et al., 2010). These

authors observed that the two orange-fleshed varieties tested had a high ß-carotene content of $>14 \mathrm{mg} / 100 \mathrm{~g}$ (fresh weight) while no ß-carotene was detected in the cream-fleshed varieties. An earlier study (Teow et al., 2007) had reported a ßcarotene range of 1.2-22.6 $\mathrm{mg} / 100 \mathrm{~g}$ (fresh weight) for orange-fleshed varieties and 0.5-5.7 mg/100g for purple-fleshed sweetpotatoes.

\subsubsection{Red-leafed lettuce}

497

Another good source of chlorogenic acids are the red-leafed varieties of lettuce. Chlorogenic acid levels in this plant were distributed across the coloured tissues, with red tissue containing approximately three times the level of green tissue and approximately eight times that of the white midrib tissue (Ferreres, Gil, Castaner, \& Tomas-Barberan, 1997; Table 1).

503

Red-leafed lettuce also possesses substantial levels of quercetin (significantly higher than green-leafed varieties) (Table 2). Quercetin levels varied across the types of tissue similarly to the distribution of phenolic acids (Ferreres et al. 1997; 
507 Table 2). Crozier et al. (1997b) also reported the outer leaves of red-leafed lettuce 508 contained $2-10$ times the quercetin content of inner leaves (Table 2).

Ferreres et al. (1997) identified and quantified substantial amounts of the

511 anthocyanin, cyanidin-3-malonylglucoside from red lettuce leaf tissues. This

512 compound had been previously isolated and identified from red onions (Ferreres, Gil, \& Tomas-Barberan, 1996).

514

\subsubsection{Red onions}

516

In a study that focussed on the growth inhibitory effect of flavonoids on 3T3-

L1 pre-adipocytes, the authors reported that quercetin had by far the highest inhibitory effect of the six flavonoids tested (Hsu \& Yen, 2006). The richest sources of dietary quercetin are red and yellow onions, while white onions contain lower levels (Crozier et al., 1997b; Harnly et al., 2006; Slimestad, Fossen, \& Vagen, 2007;

522 Table 2). Furthermore Shon, Choi, Kahng, Nam, and Sung (2004) noted that both

523 the total phenolic content and flavonoid content were high among red onions when compared to other coloured cultivars.

A recent study (Gorinstein et al., 2008) also indicated that red onions contain significant amounts of anthocyanins (46.02 $\mathrm{mg}$ of cyanidin-3-glucoside/100g dry weight) especially when compared to white onions (2.83 $\mathrm{mg}$ of cyanidin-3glucoside/100g dry weight). 
Several authors have indicated that some onion varieties contain appreciable

532 quantities of thiosulphinates (Block et al., 1992; Cheng, 2006). Pertinent to this 533 review Block et al. (1992) observed that yellow onion samples had higher levels 534 (0.35 mole\%) than red onions (0.20 mole\%).

\subsubsection{Red capsicum} (green, yellow, orange and red) capsicum was the focus of a 1997 study (Sun et al., 2007; Table 2). They reported that red capsicum had significantly higher total

541 phenolics content than the other coloured varieties. The quercetin content was significantly higher than either green or yellow capsicums but similar to the orange variety. The same authors also identified significant amounts of luteolin in red capsicum confirming the earlier report by Hollman and Arts (2000). However these

545 findings contrasted with those of Arabbi, Genovese, and Lajolo (2004) which 546 suggested that green capsicum contained higher levels of luteolin than yellow and 547 red capsicum (Table 3). Furthermore Sun et al. (2007) stated that red capsicum 548 contained the highest levels of the pigmented carotenoids (ß-carotene and capsanthin). This high content of $\beta$-carotene in red capsicum was confirmed by Stahl and Sies (2005) but the authors noted that the levels were inferior to carrot but superior to most other fruits and vegetables. This study also stated that red capsicum to be a rich source of the carotenoid lycopene (Stahl \& Sies, 2005). This carotenoid as well as being a powerful antioxidant has been suggested to have considerable anti-obesity action (Agarwal \& Rao, 2000). 
556

557

558

559

560

561

562

563

564

565

566

567

568

569

570

571

572

573

574

575

576

577

578

579

580

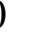

\subsubsection{Red curly kale}

Kale is reputed among vegetables to have one of the highest antioxidant capacities together with high concentrations of phenolic acids, flavonoids, carotenoids and glucosinolates (deAzevedo \& Rodriguez, 2005; Podsedek, 2007). Due to the perceived health benefits associated with anthocyanins, red/purple coloured varieties are gaining popularity (Olsen et al., 2010). These authors characterised and quantified the polyphenols in the edible leaves of the red curly kale variety Redbor. They reported that this variety was a rich source of phenolic acids (mainly $p$-coumaric, ferulic, synapic and caffeic acids), flavonols (particularly quercetin and kaempferol) and the anthocyanin cyanidin. Previous studies on the flavonol content of the green varieties (Justesen, Knuthsen, \& Leth 1998; Olsen, Aaby, \& Borge, 2009) reported significantly lower levels of quercetin and kaempferol than those reported for the red/purple varieties by Olsen et al. (2010).

In a recent study on fresh and heat treated curly kale cultivars, the authors found that the raw green samples possessed double the amount of glucosinolates when compared to the red (Olsen, Grimmer, Aaly, Saha, \& Borge, 2012). Interestingly, on heating the red cultivar the reduction in total glucosinolates was only $15 \%$ compared to $40 \%$ exhibited by the green samples. In fact the authors observed that the red cultivar was consistently more resistant to the losses of phytochemicals (polyphenols and even vitamin C) on heating than the green.

\section{Effect of cooking methods on phytochemical levels}


Data on phytochemical intake from vegetable consumption are often derived

582 from analysis of raw material. However, many vegetables are cooked in a wide

583 variety of ways before consumption. The magnitude and duration of the heating in

584 these cooking processes has a very strong influence on the levels of phytochemicals

585 remaining in the cooked product (Patras, Brunton, O'Donnell, \& Tiwari, 2010).

586 Surprisingly, given the recognised health benefits of polyphenols, literature data reporting the effect of cooking on vegetable polyphenols is scarce and often limited to only the total phenolics concentration (Ferracane et al., 2008). Studies that investigated the effect of cooking processes on the levels of potential anti-obesity phytochemicals will be reviewed.

As a general rule, the level of phytochemicals in vegetables decreases exponentially with increases in cooking duration and magnitude (Tiwari \& Cummins, 2011). However there have been reported cases where heating aids the extractability of these phytochemicals leading to an apparent concentration increase

596 (Howard, Wong, Perry, \& Klein, 1999). Therefore, the content of available phytochemicals reported in vegetables after cooking is a net result of the combined effects of degradation and leaching during cooking and changes in phytochemical extractability during analysis.

600

4.1 Effect of cooking on phenolic acids: chlorogenic acid and related compounds

602

The chlorogenic acid content of fresh-cut potato strips was reported to decrease by $50 \%, 66 \%, 63 \%$ and $71 \%$ on steaming, boiling microwaving and frying, respectively (Tudela, Cantos, Espan, Thomas-Barberan, \& Gil, 2002). Support for 
606 this observation was provided by Miglio. Chiavaro, Visconti, Fogliano, and Peregrini

607 (2008), who reported a general decrease in phenolic acids for all the vegetables that

608 underwent cooking. Other studies involving potato found that chlorogenic acids were

609 absent in baked potatoes (Friedman, 1997), while frying resulted in losses of over

$61050 \%$ in potato and carrot (Friedman, 1997; Miglio et al., 2008). A possible exception

611 was provided by Takenaka et al. (2006) when they reported a slight increase in the

612 chlorogenic acid isomers (3-caffeoylquinic, 4-caffeoylquinic,3,4-decaffeoylquinic and

613 4,5-dicaffeoylquinic acids) on boiling sweetpotatoes. A later investigation (Truong et

614 al., 2007) supported this finding when they stated that steam cooking resulted in

615 slight increases in the concentration of individual phenolic acids identified in

616 sweetpotato root tissues. However, prolonged boiling resulted in losses of

617 chlorogenic acid of 60 - 100\% (Friedman 1997; Takenaka et al., 2006; Miglio et al.,

618 2008). It was suggested that the slight increase in chlorogenic acid could be

619 attributed to release of bound phenolics and the inactivation of polyphenol oxidase

620 during steaming (Truong et al., 2007). Polyphenol oxidase (PPO) is an enzyme

621 present in many plants and on tissue damage, e.g. cutting, the enzyme catalyses the

622 formation of a brown pigment from phenolic compounds. Artichoke is a vegetable

623 that has a very high PPO activity when raw. On cooking (steaming, boiling and

624 frying), this vegetable shows a significant increase in the concentration of the

625 caffeoylquinic acid (Ferracane et al., 2008). It was suggested that the cooking

626 treatments resulted in PPO inactivation that reduced the enzymatic degradation

627 compared to the raw artichoke of the phenolic acids. In the same study, cooking

628 reduced levels of flavones (e.g. apigenin) which the authors attributed to the

629 increased thermal degradation of these compounds. 
631

632

633

634

635

636

637

638

639

640

641

642

643

644

645

646

647

648

649

650

651

652

653

4.2 Effect of cooking on flavonols: quercetin and related compounds

Reductions of between $44-53 \%$ in the levels of the quercetin glycosides were reported during 60 min boiling of onions (Rodrigues, Perez-Gregorio, Garcia-Falcon, \& Simal-Gandara, 2009). An earlier study had demonstrated that $15 \%$ of quercetin was lost on boiling onions for only 5 min (Lombard, Peffley, Geoffriau, Thompson, \& Herring, 2005). Both groups of authors suggested that this reduction was due to thermal degradation of the quercetin but they could not discount leaching of the water soluble quercetin. This loss of quercetin confirmed the experiments of Crozier et al. (1997b) who reported that boiling and microwaving reduced levels by $75 \%$ and $64 \%$, respectively. Frying onions in sunflower oil resulted in a reduction of only $21 \%$, possibly due to the less effective extraction of the hydrophilic quercetin by the hot oil compared to hot water. These researchers also reported a similar reduction of quercetin in tomatoes after undergoing the same cooking treatments (Crozier et al., 1997b).

.

Quercetin and kaempferol levels in broccoli were less affected by steaming (losses of $40 \%$ and $1 \%$, respectively) than by frying ( $70 \%$ and $45 \%$, respectively) and boiling (90\% and 85\%, respectively) (Miglio et al., 2008). Greater diffusion of phytochemicals into an aqueous, boiling cooking medium as opposed to steaming and frying is to be expected for these water-soluble compounds and accounts for the different levels observed (Miglio et al., 2008). 

quercetin and myricetin by $25 \%$, while a 60 sec treatment resulted in losses of $50 \%$. Treatment for further $60 \mathrm{sec}$ resulted in $80 \%$ loss of myricetin (Chu et al., 2000).

\subsection{Effect of cooking on flavones: Iuteolin and apigenin}

659 $30 \mathrm{sec}$ and $65 \%$ loss after $120 \mathrm{sec}$ (Chu et al., 2000). Steaming resulted in losses of $25 \%$ of apigenin in globe artichokes, while $35 \%$ was lost on boiling and $60 \%$ by frying (Ferracane et al., 2008). To date the authors could find no references that reported the effects of cooking on luteolin levels.

\subsection{Effect of cooking on anthocyanins and carotenoids}

667

There is little published information on the thermal stability of anthocyanins in vegetables. However, Oliveira, Amaro, Pinho, and Ferreira (2010) observed a 12\% to $42 \%$ reduction of anthocyanins in cooked blueberries during progressive heating 671 from $12^{\circ}$ to $99^{\circ} \mathrm{C}$ for $60 \mathrm{~min}$. They suggested anthocyanins are naturally unstable 672 and degradation is primarily caused by oxidation. This instability had been previously 673 noted by Sadilova, Stintzing, and Carle (2006) in strawberry, elderberry and black carrot concentrates. These authors suggested the degradation mechanism is due to hydrolysis of the anthocyanin sugar moiety leading to formation of a phenolic non-

676 bioactive aglycone. 
Isomerisation and oxidation reactions upon heating of carotenoids have been

679 reported (Rodriguez-Amaya, 1999). Even though carotenoids are susceptible to

680 thermal isomerisation most of these compounds appear to be much more heat stable

681 than anthocyanins (Leong \& Oey, 2012; Nguyen, Francis, \& Schwartz, 2001; Nguyen

682 \& Schwartz, 1998). Van Jaarsveld, Marais, Harmse, Nestle, and Rodriguez-Amaya

683 (2006) studied the effect of thermal processing on ß-carotene in orange-fleshed 684 sweetpotato and found minimal losses after boiling for 20 and $30 \mathrm{~min}$. These small

685 losses were later confirmed by Rautenbach et al. (2010) when they observed an

686 average decrease of $9.7 \%$ on boiling sweetpotato for $12 \mathrm{~min}$. These results seem

687 contradictory to earlier studies of Hagenimana, Carey, Gichuki, Oyungand, and 688 Imungi (1999) and K'osambo, Carey, Misra, Wilkes, and Hagenimana (1998) where 689 decreases of $30.6 \%$ and $14-59 \%$ for total carotenoids on boiling for 30 min were reported. A study that evaluated the effects of heating i.e. $98^{\circ} \mathrm{C}$ for $10 \mathrm{~min}$ on carotenoids in carrots and red capsicum reported no change in the content in the red

692 capsicum but a significant decrease in the carrots. There are several studies that 693 testify to the thermal stability of the carotenoid lycopene, mostly focussing on tomato and tomato products (Gupta, Balasubramaniam, Schwartz, \& Francis, 2010; Kessy, Zhang, \& Zhang, 2011; Nguyen \& Schwartz, 1998).

\subsection{Effect of cooking on organosulphurs}

698

Considering the well recorded benefits of the thiosulphinates in Allium vegetables surprisingly few studies have evaluated the impact of cooking on these levels. In fact most of the cooking studies have focussed on monitoring changes in their anti-thrombotic activity, a property attributed to allicin and the thiosulphinates 
703 (Ali, 1995; Cavagnaro, Camargo, Galmarini, \& Simon, 2007; Chen, Chen, Tsa, \&

704 Jen, 2000). Boiling (15-30 min) was seen to completely inhibit anti-thrombotic activity

705 in uncrushed garlic and Welsh onion (Ali, 1995; Chen et al., 2000) which the authors

706 suggested was possibly due to the inactivation of the allinase before it could produce

707 any anti-thrombotic agents. A later study confirmed that; 1) allicin and

708 thiosulphinates were responsible for the anti-thrombotic activity and 2) the lack of 709 anti-thrombotic activity found previously (Ali, 1995; Chen et al., 2000) in boiled

710 samples was due to allinase inactivation thus preventing the formation of the

711 bioactive thiosulphinates (Cavagnaro et al., 2007).

712

713

Glucosinolates and hydrolysis products can be lost following cooking which

714

may reduce glucosinolate levels by $30-60 \%$, depending on the method (e.g.,

715 conventional, microwave, high pressure), cooking intensity, and on the type of glucosinolate present (Ciska \& Kozlowska, 2001; Vallejo, Thomas-Barberan, \&

717 Garcia, 2002). Glucosinolate breakdown products are barely detected after

718 prolonged cooking, with the exception of several non-bioactive compounds (Macleod

\& Macleod, 1968). Handling, storage and cooking methods that provide minimal loss of bioactivity have yet to be determined. However, a paper by Song and Thornalley (2007) went some way to rectifying this when they outlined several cooking methods that preserved the glucosinolates as well as retaining some of the myrosinase thus allowing an increase in the conversion of glucosinolates to isothiocyanates. Their investigation involved seven major glucosinolates in broccoli, Brussels sprouts, cauliflower and cabbage and their stability under different cooking conditions. The findings of this study were confirmed recently by Aires, Carvalho, and Rosa (2012)

727 when they reported that steaming of vegetables was the most successful in 
preserving glucosinolates as opposed to boiling which caused glucosinolate losses of up to $81 \%$.

\section{Conclusions}

Scientific investigations using cell culture and animal model studies demonstrate that polyphenols derived from vegetables can induce lipolysis, decrease lipid accumulation and induce apoptosis in adipose tissue. These mechanisms indicate potential anti-obesity properties that lend themselves to testing in human clinical studies. In addition to possible effects on adipocytes themselves, the anti-inflammatory properties reported for some vegetable phytochemicals suggest a powerful adjunct to dietary energy restriction in obesity-related chronic disease management.

This review does not provide an exhaustive list of phytochemcials found in vegetables. As research identifies other compounds that modify the adipocyte life cycle or possess high anti-inflammatory activity, and knowledge of the human adipocyte lifecycle expands, additional vegetables may emerge as having the same anti-obesity potential. To date the richest vegetable sources of potential anti-obesity phytochemicals appear to be: the red varieties of onion, lettuce, capsicum and curly kale; and orange-fleshed varieties of sweetpotato. The cooking method influences the levels of these phytochemicals in vegetables. Boiling vegetables results in the greatest losses of water soluble phytochemicals such as the polyphenolics, through leaching, thermal degradation and oxidation. In contrast gentle stir-frying appears to result in the least losses. 
754 The cell signalling pathways which control the initiation and development of

755 obesity and related chronic diseases are complex and interconnected. It has been

756 shown that appropriate combinations of dietary phytochemicals can interact

757 positively with these pathways. Therefore promotion of the consumption of

758 vegetables that are rich in a wide variety of potentially anti-obesity phytochemicals

759 and which are cooked to best maintain the levels of these agents may assist in the

760 dietary control of obesity and related chronic diseases through additive or even

761 synergistic mechanisms.

762

763 Acknowledgements

764

765

This study was funded by Horticulture Australia Limited (VG09037).

766

767

I wish to thank the following people for their contribution to proof-reading the

manuscript as well as providing informed comments and suggestions: Dr Gloria

Karagianis of Agri-Science Queensland, DAFF and Emeritus Professor Christa

Critchley. Also thanks to Avis Houlihan formerly of DAFF who undertook much of the

771 work in obtaining references, collating and developing the earlier versions of this

772 manuscript.

773

774

775 
777

778

779

780

781

782

783

784

785

786

787

788

789

790

791

792

793

794

795

796

797

798

799

800

801

802

803

804

805

806

807

808

809

810

811

812

813

814

815

816

817

818

819

820

821

822

823

824

\section{References}

Adams, J. M., \& Cory, S. (1998). The Bcl-2 protein family: arbiters of cell survival. Science, 281, 1322-6.

Agarwal, S., \& Rao, A. V. (2000). Tomato lycopene and its role in human health and chronic diseases. Canadian Medical Association Journal, 163, 739-44.

Ahn, J., Lee, H., Kim, S., Park, J., \& Ha, T. (2008). The anti-obesity effect of quercetin is mediated by the AMPK and MAPK signalling pathways. Biochemical Biophysical Research Communication, 373, 545-9.

Al-Fayez, M., Cai, H., Tunstall, R., Steward, W. P., \& Gescher, A. J. (2006). Differential modulation of cyclooxygenase-mediated prostaglandin production by the putative cancer chemopreventive flavonoids tricin, apigenin and quercetin. Cancer Chemotherapy and Pharmacology, 58, 816-825.

Ali, M. (1995). Mechanism by which garlic (Allium sativum) inhibits cyclooxygenase activity. Effect of raw versus boiled garlic extract on the synthesis of prostanoids. Prostaglandins Leukotrienes Essential Fatty Acids, 53, 397-400.

Aires, A., Carvalho, R., \& Rosa, E. (2012). Glucosinolate composition of Brassica is affected by postharvest, food processing and myrosinase activity. Journal of Food Processing and Preservation, 36, 214-224.

Arabbi, P. R., Genovese, M. I., \& Lajolo, F. M. (2004). Flavonoids in vegetable foods commonly consumed in Brazil and estimated ingestion by the Brazilian population. Journal of Agricultural and Food Chemistry, 52, 1124-1131.

Astrup, A. (2001). Healthy lifestyles in Europe: prevention of obesity and type II diabetes by diet and physical activity. Public Health Nutrition, 4, 499-515.

Azzini, E., Bugianesi, R., Romano, F., Di Venere, D., Miccadei, S., Durazzo, A., et al. (2007). Absorption and metabolism of bioactive molecules after oral consumption of cooked edible heads of Cynara scolymus L. (cultivar Violetto di Provenza) in human subjects: a pilot study. British Journal of Nutrition, 97, 963-969.

Badimon, L., Vilahur, G., \& Padro, T. (2010). Nutraceuticals and atherosclerosis: human trials. Cardiovascular Therapeutics, 28(4), 202-15.

Baile, C. A., Yang, J. Y., Rayalam, S., Hartwell, D. L., Lai, C. Y., \& Andersen, C. (2011). Effect of reserveratrol on fat mobilisation. Annals of the New York Academy of Sciences, 1215, 40-47.

Birari, R. B., \& Bhutani, K. K. (2007). Pancreatic lipase inhibitors from natural sources: unexplored potential. Drug Discovery Today, 12, 879-889.

Block, E., Naganathan, S., Putman, D., \& Zhao, S-H. (1992). Allium chemistry: HPLC analysis of thiosulphinates from onion, garlic, wild garlic, leek, scallion, shallot, elephant garlic, chive and chinese chive. Journal of Agricultural and Food Chemistry, 40, 2418-2430.

Burrows, T. L., Warren, J. M., Colyvas, K., Garg, M. L., \& Collins, C. E. (2009). Validation of overweight children's fruit and vegetable intake using plasma carotenoids. Obesity, 17(1), 162-8.

Camire, M. E., Kubow, S., \& Donnelly, D. J. (2009) Potatoes and human health. Critical Reviews in Food Science and Nutrition, 49, 823-840.

Cartea, M. E., \& Velasco, P. (2008). Glucosinolates in Brassica foods: bioavailability in food and significance for human health. Phytochemistry Reviews, 7, 213229. 
831

832

833

834

835

836

837

838

839

840

841

842

843

844

845

846

847

848

849

850

851

852

853

854

855

856

857

858

859

860

861

862

863

864

865

866

867

868

869

870

871

872

873

874
Cavagnaro, P. F., Camargo, A., Galamarini, C. R., \& Simon, P. W. (2007). Effect of cooking on garlic (Allium sativum L.) antiplatelet activity and thiosulphinates content. Journal of Agricultural and Food Chemistry, 55, 1280-1288.

Chan, M. M., Fong, D., Soprano, K. J., Holmes, W. F., \& Heverling, H. (2003). Inhibition of growth and sensitization to cisplatin-mediated killing of ovarian cancer cells by polyphenolic chemopreventive agents. Journal of Cellular Physiology, 194, 63-70.

Chen, J. H., Chen, H. I., Tsa, S. J., \& Jen, C. J. (2000). Chronic consumption of raw but not boiled Welsh onion juice inhibits rat platelet function. Journal of Nutrition, 130, 34-37.

Cheng, L-H. (2006). Analysis of allicin and quercetin and functional food development from several Allium vegetables. Master of Science Thesis, Tatung University, Republic of China.

Cho, H. J., Seon, M. R., Lee, Y. M., Kim, J., Kim, J-K., Kim, S. G., \& Park, J. H. Y. (2008). 3,3-diindoylmethane suppresses the inflammatory response to lipopylsaccharide in murine macrophages. Journal of Nutrition, 138, 17-23.

Chu, Y-H., Chang, C-L., \& Hsu, H-F. (2000). Flavonoid content of several vegetables and their antioxidant activity. Journal of the Science of Food and Agriculture, 80, 561-566.

Chuang, C. C., Martinez, K., Xie, G., Kennedy, A., Bumrungpert, A., Overman, A., et al. (2010). Quercetin is equally or more effective than resveratrol in attenuating tumor necrosis factor-\{alpha\}-mediated inflammation and insulin resistance in primary human adipocytes. American Journal of Clinical Nutrition, 92(6), 1511-21.

Ciska, E., \& Kozlowska, H. (2001). The effect of cooking on the glucosinolates content in white cabbage. European Food Research and Technology, 212, 582-587.

Clifford, M. N. (2000). Anthocyanins-nature, occurrence and dietary burden. Journal of the Science of Food and Agricultur, 80, 1063-72.

Crozier, A., Jensen, E., Lean, M. E., \& McDonald, M S. (1997a). Quantitative analysis of flavonoids by reversed phase high-performance liquid chromatography. Journal of Chromatography, 761, 315.

Crozier, A., Lean, M. E. J., McDonald, M. S., \& Black, C. (1997b). Quantitative analysis of the flavonoid content of commercial tomatoes, onions, lettuce, and celery. Journal of Agricultural and Food Chemistry, 45, 590-595.

de Azevedo, C. H., \& Rodriguez-Amaya, D. B. (2005). Cartenoid composition of kale as influenced by maturity, season and minimal processing. Journal of the Science of Food and Agriculture, 85, 591-597.

Dey, P. M., \& Harborne, J. B. (1989). Plant phenolics. In J. B. Harborne (Ed.) Methods in plant biochemistry, vol1:. London: Academic press

El Gharras, H. (2009). Polyphenols: food sources, properties and applications - a review. Journal of Food Science and Technology, 44, 2512-8.

Elkayam, A., Mirelman, D., Peleg, E., Wilchek, M., Miron, T., Rabinkov, A., et al. (2003). The effects of allicin on weight in fructose-induced hyperinsulinemic, hyperlipidemic, hypertensive rats. American Journal of Hypertension, 16, 1053-1056.

Fahey, J. W., Zhang, Y., \& Talalay, P. (1997). Broccoli sprouts: an exceptionally rich source of inducers of enzymes that protect against chemical carcinogens. Proceedings of the National Academy of Sciences of the United States of America, 94, 10367-10372. 
881

882

883

884

885

886

887

888

889

890

891

892

893

894

895

896

897

898

899

900

901

902

903

904

905

906

907

908

909

910

911

912

913

914

915

916

917

918

919

920

921

922

923

924

Fang, X. K., Gao, J., \& Zhu, D. N. (2008). Kaempferol and quercetin isolated from Euonymus alatus improve glucose uptake of 3T3-L1 cells without adipogenesis activity. Life Science, 82(11-12), 615-22.

Ferracane, R., Pellegrini, N., Visconti, A., Graziani, G., Chiavaro, E., Miglio, C., \& Fogliano, V. (2008). Effects of different cooking methods on antioxidant profile, antioxidant capacity, and physical characteristics of artichoke. Journal of Agricultural and Food Chemistry, 56, 8601-8608.

Ferreres, F., Gil, M. I., Castaner, M., \& Tomas-Barberan, F. A. (1997). Phenolic metabolites in red pigmented lettuce (Lactuca sativa). Changes with minimal processing and cold storage. Journal of Agricultural and Food Chemistry, 45, 4249-4254.

Ferreres, F., Gil, M. I., \& Tomas-Barberan, F. A. (1996). Anthocyanins and flavonoids from shredded red onion and changes during storage in perforated films. Journal of Food Research International, 29, 389-395.

Friedman, M. (1997). Chemistry, biochemistry, and dietary role of potato polyphenols. a review. Journal of Agricultural and Food Chemistry, 45, 15231540.

Furuyashiki, T., Nagayasu, H., Aok,i Y., Bessho, H., Hashimato, T., Kanazawa, K., \& Ashida, H. (2004). Tea catechin suppresses adipocyte differentiation accompanied by down-regulation of PPARgamma2 and C/EBPalpha in 3T3L1 cells. Bioscience Biotechnology Biochemistry, 68(11), 2353-9.

Gennaro, L., Leonardi, C., Esposito, F., Salucci, M., Maiani, G., Quaglia, G., \& Fogliano, V. (2002). Flavonoid and carbohydrate contents in Tropea red onions: Effects of homelike peeling and storage. Journal of Agricultural and Food Chemistry, 50, 1904-1910.

Gonzalez-Castejon, M., \& Rodriguez-Casado, A. (2011). Dietary phytochemicals and their potential effects on obesity : a review. Journal of Pharmacological Research, 64, 438-455.

Gorinstein, S., Leontowicz, H., Leontowicz, M., Namieshik, J., Najman, K., Drzewiecki, J., et al. (2008). Comparison of the main bioactive compounds and antioxidant activites in garlic and white and red onions after treatment protocols. Journal of Agricultural and Food Chemistry, 56(12), 4418-4426.

Grundy, S. (2012). Pre-diabetes, metabolic syndrome and cardiovascular risk. Journal of the American College Cardiology, 59, 635-43.)

Gupta, R., Balasubramaniam, V. M., Schwartz, S. J., \& Francis, D. M. (2010). Journal of Agricultural and Food Chemistry, 58, 8305-8313.

Hagenimana, V., Carey, E. E., Gichuki, S. T., Oyunga, M. A., \& Imungi, J. K. (1999). Cartenoid contents in fresh, dried and processed sweetpotato products. Ecology of Food and Nutrition, 37, 455-73.

Halkier, B. A., \& Gershenzon, J. (2006). Biology and biochemistry of glucosinolates. Annual Review of Plant Biology, 57, 303-333.

Harnly, J. M., Doherty, R. F., Beecher, G. R., Holden, J. M., Haytowitz, D. B., Bhagwat, S., \& Gebhardt, S. (2006). Flavonoid content of US fruits, vegetables, and nuts. Journal of Agricultural and Food Chemistry, 54, 99669977.

Harrison, H. F., Mitchell, T. R., Peterson, J. K., Wechter, W. P., Majetich, G. F., \& Snook, M. E. (2008). Contents of caffeoylquinic acid compounds in the storage roots of sixteen sweetpotato genotypes and their potential biological activity. Journal of the American Society of Horticultural Science, 133, 492500 . 
Heiss, E., Herhaus, C., Klimo, K., Bartsch, H., \& Gerhauser, C. (2001). Nuclear factor kappa B is a molecular target for sulforaphane-mediated antiinflammatory mechanisms. Journal of Biological Chemistry, 276, 3200832015.

Hermlswarya, S., \& Doble, M. (2006). Potential synergism of natural products in the treatment of cancer. Phytotherapy Research, 20, 239-49.

Herrmann, K. (1989). Occurrence and content of hydroxycinnamic and hydroxybenzoic acid compounds in foods. Critical Reviews in Food Science and Nutrition, 28, 315-347.

Hollman, P. C., \& Arts, I. C. (2000). Flavonols, flavones and flavanols - nature, occurrence and dietary burden. Journal of the Science of Food and Agriculture, 80, 1081-1093.

Howard, L. A., Wong, A. D., Perry, A. K., \& Klein, B. P. (1999). ß-carotene and ascorbic acid retention in fresh and processed vegetables. Journal of Food Science, 64(5), 929-936.

Hsu, C. L., \& Yen, G. C. (2006). Introduction of cell apoptosis in 3T3-L1 preadipocytes by flavonoids is associated with antioxidant activity. Molecular Nutrition and Food Research, 50, 1072-9.

Itakura, Y., Ichikawa, M., Mori, Y., Okino, R., Udayama, M., \& Morita, T. (2001). How to distinguish garlic from the other Allium vegetables. Journal of Nutrition, 131, 9635-9675.

Justesen, U., Knuthsen, P., \& Leth, T. (1998). Quantitative analysis of flavonols, flavones and flavanones in fruits, vegetables and breverages by highperformance liquid chromatography with photo-diode array and mass spectrometric detection. Journal of Chromatography, 799, 101-110.

Kamei, N., Tobe, K., Suzuki, R., Ohsugi, M., Watanabe, T., Kubota, N. et al. (2006). Overexpression of monocyte chemoattractant protein-1 in adipose tissues causes macrophage recruitment and insulin resistance. Journal of Biological Chemistry, 281, 26602-26614.

Kessy, H., Zhang, H., \& Zhang, L. (2011). A study on thermal stability of lycopene in tomato in water and oil food systems using response surface methodology, International Journal of Food Science and Technology, 46, 209-215.

Kissen, R., Rossiter, J. T., \& Bones, A. M. (2009). The 'mustard oil bomb': not so easy to assembe? Localization, expression and distribution of the components of the myrosinase system. Phytochemistry Reviews, 8, 69-86.

Koroleva, O. A., Davies, A., Deeken, R., Thorpe, M. R., Deri-Thomas, A., \& Hedrich, R. (2000). Identification of a new glucosinolate-rich cell type in Arabidopsis flower stalk. Plant Physiology, 124, 599-608.

K'osambo, L. M. K., Carey, E. E., Misra, A. K., Wilkes, J., \& Hagenimana, V. (1998). Influence of age, farming site and boiling on pro-vitamin $A$ content in sweetpotato (Ipomoea batatas (L) Lam) storage roots. Journal of Food Composition and Analysis, 11, 305-21.

Kruger, J., Galuska, D. A., Serdula, M. K., \& Jones, D. A. (2004). Attempting to lose weight: specific practices among U.S. adults. American Journal of Preventive Medicine, 26, 402-6.

Kuppusamy, U. R., \& Das, N. P. (1992). Effects of flavonoids on cyclic AMP phosphodiesterase and lipid mobilization in rat adipocytes. Biochemical Pharmacology, 44, 1307-15. 
Leong, S. Y., \& Oey, I. (2012) Effects of processing on anthocyanins, carotenoids and vitamin $C$ in summer fruits and vegetables. Journal of Food Chemistry, 133, 1577-1587.

Lombard, K., Peffley, E., Geoffriau, E., Thompson, L., \& Herring, A. (2005). Quercetin in onion (Allium cepa L.) after heat-treatment simulating home preparation. Journal of Food Composition and Analysis, 18, 571-581.

MacLeod, A., \& MacLeod, G. (1968). Volatiles of cooked cabbage. Journal of the Science of Food and Agriculture, 19, 273-277.

Marinou, K., Tousoulis, D., Antonopoulos, A. S., Stefanadi, E., \& Stefanadis, C. (2010). Obesity and cardiovascular disease: from pathophysiology to risk stratification. International Journal of Cardiology, 138, 3-8.

Mattila, P., \& Hellstrom, J. (2007). Phenolic acids in potatoes, vegetables, and some of their products. Journal of Food Composition and Analysis, 20, 152-160.

Mattila, P., \& Kumpulainen, J. (2002). Determination of free and total phenolic acids in plant-derived foods by HPLC with Diode-Array Detection. Journal of Agricultural and Food Chemistry, 50, 3660-3667.

Matusheski, N. V., Juvik, J. A., \& Jeffery, E. H. (2004). Heating decreases epithiospecifier protein activity and increases sulforaphane in broccoli. Phytochemistry, 65, 1273-1281.

Meyer, H., Bolarinwa, A., Wolfram, G., \& Linseisen, J. (2006). Bioavailability of apigenin from apiin-rich parsley in humans. Annals of Nutrition and Metabolism, 50, 167-172.

Miglio, C., Chiavaro, E., Visconti, A., Fogliano, V., \& Pellegrini, N. (2008). Effects of different cooking methods on nutritional and physicochemical characteristics of selected vegetables. Journal of Agricultural and Food Chemistry, 56, 139147.

Miron, T., Shin, G., Feigenblat, L., Weiner, D., Mirelman, M., Wilcheck, A., \& Rabinkov, A. (2002). A spectrophotometric assay for allicin and allinase (alliinlyase) with a chromogenic thiol reaction of 4-mercaptopyridine with thiosulfinates. Analytical Biochemistry, 307-76-83.

Morikawa, K., Ikeda, C., Nonaka, M., \& Suzuki, I. (2007). Growth arrest and apoptosis induced by quercetin is not linked to adipogenic conversion of human preadipocytes. Metabolism-Clinical and Experimental, 56, 1656-1665.

Mulvihill, E. E., \& Huff, M. W. (2010). Antiatherogenic properties of flavonoids: implications for cardiovascular health. Canadian Journal of Cardiology, 26(Suppl A), 17A-21A.

Naczk, M., \& Shahidi, F. (2006). Phenolics in cereals, fruits and vegetables: Occurrence, extraction and analysis. Journal of Pharmaceutical and Biomedical Analysis, 41(5), 1523-1542.

Nelson-Dooley, C., Della-Fera, M. A., Hamrick, M., \& Baile, C. A. (2005). Novel treatments for obesity and osteoporosis: targeting apoptotic pathways in adipocytes. Current Medicinal Chemistry, 12, 2215-2225.

Nguyen, M. L., Francis, D., \& Schwartz, S. (2001). Thermal isomerisation susceptibility of carotenoids in different tomato varieties. Journal of the Science of Food and Agriculture, 81, 910-917.

Nguyen, M. L., \& Schwartz, S. J. (1998). Lycopene stability during food processing. Proceeding of the Society for Experimental Biology and Medecine, 218, 101.

Nishikawa, T., Yamada, N., Hattori, A., Fukada, H., \& Fujino, T. (2002). Inhibion by ajoene of skin tumour promotion in mice. Bioscience, Biotechnology and Biochemistry, 66, 2221-2223. 
1023

1024

1025

1026

1027

1028

1029

1030

1031

1032

1033

1034

1035

1036

1037

1038

1039

1040

1041

1042

1043

1044

1045

1046

1047

1048

1049

1050

1051

1052

1053

1054

1055

1056

1057

1058

1059

1060

1061

1062

1063

1064

1065

1066

1067

1068

1069

1070

1071
Nuutila, A. M., Kammiovirta, K., \& Oksman-Caldentey, K-M. (2002). Comparison of methods for the hydrolysis of flavonoids and phenolic acids from onion and spinach for HPLC analysis. Food Chemistry, 76, 519-25.

Nuutila, A. M., Puupponen-Pimia, R., Aarni, M., \& Oksman-Caldentey, K. M. (2003.) Comparison of antioxidant activities of onion and garlic extracts by inhibition of lipid peroxidation and radical scavenging activity. Food Chemistry, 81(4), 485-493.

Oliveira, C., Amaro, L. F., Pinho, O., \& Ferreira, I. M. P. L. V. O. (2010). Cooked blueberries: anthocyanin and anthocyanidin degradation and their radicalscavenging activity. Journal of Agricultural and Food Chemistry, 58(6), 90069012.

Olsen, H., Aaby, K., \& Borge, G. I. A. (2009). Characterisation and quantification of flavonoids and hydroxycinnamic acids in curly kale (Brassica oleracea L. convar. acephala var. sabellica) by HPLC-DAD-ESI-MSn. Journal of Agricultural and Food Chemistry, 57, 2816-2825.

Olsen, H., Aaby, K., \& Borge, G. I. A. (2010). Characterization, quantification, and yearly variation of the naturally occurring polyphenols in a common red variety of curly kale (Brassica oleracea L. convar. acephala var. sabellica cv. 'Redbor'). Journal of Agricultural and Food Chemistry, 58, 11346-11354.

Olsen, H., Grimmer, S., Aaby, K., Saha, S., \& Borge, G. I. A. (2012). Antiproliferative effects of fresh and thermal processed green and red cultivars of curly kale (Brassica oleracea L. convar. acephala var. sabellica). Journal of Agricultural and Food Chemistry, 60, 7375-7383.

Olsson, M., Gustavsson, K. E., \& Vagen, I. M. (2010). Quercetin and isorhamnetin in sweet and red cultivars of onion (Allium cepa L.) at harvest, afer field curing, heat treatment and storage. Journal of Agricultural and Food Chemistry, 58(4), 2323-2330.

Padda, M. S., \& Picha, D. H. (2007). Antioxidant activity and phenolic composition in 'Beauregard' sweetpotato are affected by root size and leaf age. Journal of the American Society for Horticultural Science, 132, 447-451.

Padda, M. S., \& Picha, D. H. (2008). Quantification of phenolic acids and antioxidant activity in sweetpotato genotypes. Scientia Horticulturae, 119, 17-20.

Pan, M-H., Lai, C-S., \& Ho, C-T. (2010). Anti-inflammatory activity of natural dietary flavonoids. Food \& Function, 1, 15-31.

Park, T., \& Kim, Y. (2011). Phytochemicals as potential agents for prevention and treatment of obesity and metabolic diseases. In Bentham science. Antiobesity drug discovery and development, 1, 1-48.

Park, H. J., Kim, S.H., \& Kim, Y. S. (2009). Luteolin inhibits adipogenic differentiation by regulating PPAR gamma activation. Biofactors, 35(4), 373-379.

Park, H. J., Yang, J. Y., \& Amabati, S. (2008). Combined effects of genistein, quercetin and resveratrol in human and 3T3-L1 adipocytes. Journal of Medicinal Food, 11(4), 773-783.

Patras, A., Brunton, N. P., O'Donnell, C., \& Tiwari, B. K. (2010). Effect of thermal processing on anthocyanin stability in foods, mechanisms and kinetics of degradation. Trends in Food Science \& Technology, 21(1), 3-11.

Piper, A. J. (2011). Obesity hypoventilation syndrome - the big and the breathless. Sleep Medicinal Review, 15(2), 79-89.

Podsedek, A. (2007). Natural antioxidants and antioxidant capacity of Brassica vegetables : a review. LWT- Food Science and Technology, 40, 1-11. 
1072

1073

1074

1075

1076

1077

1078

1079

1080

1081

1082

1083

1084

1085

1086

1087

1088

1089

1090

1091

1092

1093

1094

1095

1096

1097

1098

1099

1100

1101

1102

1103

1104

1105

1106

1107

1108

1109

1110

1111

1112

1113

1114

1115

1116

1117

1118

1119
Popkin, B. M. (2009). The world is fat: the fads, trends, policies, and products that are fattening the human race. New York: Avery Trade/Penguin Group.

Popkin, B. M., Kim, S., Rusev, E. R., Du, S., \& Zizza, C. (2006). Measuring the full economic costs of diet, physical activity and obesity - related chronic diseases. Obesity Review, 7, 271-93.

Porter, A. J. R., Morton, A. M., Kiddle, G., \& Wallsgrove, R. M. (1991). Variation in thr glucosinolate content of oilseed (Brassica napus L): effects of leaf age and position. Annals of Applied Biology, 118, 461-467.

Rautenbach, F., Faber, M., Laurie, S., \& Laurie, R. (2010). Antioxidant capacity and antioxidant content in roots of 4 sweetpotato varieties. Journal of Food Science, 75, C400-C405.

Rayalam, S., Della-Fera, M. A., \& Baile, C. A. (2008). Phytochemicals and regulation of the adipocyte life cycle. Journal of Nutritional Biochemistry, 19, 717-726.

Rawson, A., Koidis, A., Rai, D. K., Tuohy, M., \& Brunton, N. (2010). Influence of sous vide and water immersion processing on polyacetylene content and instrumental color of parsnip (Pastinaca sativa) disks. Journal of Agricultural and Food Chemistry, 58(13), 7740-7747.

Rawson, A., Patras, A., Tiwari, B. K., Noci, F., Koutchma, T., \& Brunton, N. (2011). Effect of thermal and non thermal processing technologies on the bioactive content of exotic fruits and their products: review of recent advances. Food Research International, 44(7), 1875-1887.

Rodrigues, A. S., Perez-Gregorio, M. R., Garcia-Falcon, M. S., \& Simal-Gandara, J. (2009). Effect of curing and cooking on flavonols and anthocyanins in traditional varieties of onion bulbs. Food Research International, 42(9), 13311336.

Rodriguez-Amaya, D. B. (1999). Changes in carotenoids during processing and storage of foods. Archivos Latinoamericanos de Nutricion, 49, 38S-47S

Sadilova, E., Stintzing, F. C., \& Carle, R. (2006) Thermal degradation of acylated and nonacylated anthocyanins. Journal of Food Science, 71(8), C504-C512.

Sahu, S. C. (2002). Dual role of organosulphur compounds in foods: a review. Journal of Enviromental Science and Health. Part C. Enviromental Carcinogenesis \& Ecotoxicology Reviews, 20, 61-76.

Santos, A. P., Rogero, M. M., \& Bastos, D. H. (2010). Edible plants, their secondary metabolites and anti-obesogenic potential. Recent Patents on Food Nutrition and Agriculture, 2(3), 195-212.

Sartipy, P., \& Loskutoff, D. J. (2003). Monocyte chemoattractant protein 1 in obesity and insulin resistance. Proceedings of the National Academy of Sciences of the United States of America, 100, 7265-7270.

Sasaki, R., Nishimura, N., Hoshino, H., Isa, Y., Kadowaki, M., Ichi, T.,et al. (2007). Cyanidin 3-glucoside ameliorates hyperglycemia and insulin sensitivity due to down regulation of retinol binding protein 4 expression in diabetic mice. Biochemical Pharmacology, 74, 1619-1627.

Shon, M. Y., Choi, S. D., Kahng, G. C., Nam, S. H., \& Sung, N. J. (2004). Antimutagenic, antioxidant and free radical scavenging activity of ethyl acetate extracts from white, yellow and red onions. Food and Chemical Toxicology, 42, 659-666.

Siegers, C. P., Steffen, B., Robke, A., \& Pentz, R. (1999). The effects of garlic preparations against human tumour cell proliferation. Phytomedicine, 6, 7-11. 
1120

1121

1122

1123

1124

1125

1126

1127

1128

1129

1130

1131

1132

1133

1134

1135

1136

1137

1138

1139

1140

1141

1142

1143

1144

1145

1146

1147

1148

1149

1150

1151

1152

1153

1154

1155

1156

1157

1158

1159

1160

1161

1162

1163

1164

1165

1166

1167

1168
Singh, J., Upadhyay, A. K., Prasad, K., Bahadur, A., \& Rai, M. (2007). Variability of carotenes, vitamin C, E and phenolics in Brassica vegetables. Journal of Food Composition and Analysis, 20(2), 106-112.

Singla, P., Bardoloi, A., \& Parkash, A. A. (2010). Metabolic effects of obesity: a review. World Journal Diabetes, 1, 76-88.

Slimestad, R., Fossen, T., \& Vagen, I. M. (2007). Onions: a source of unique dietary flavonoids. Journal of Agricultural and Food Chemistry, 55(25), 10067-80.

Song, L., \& Thornalley, P. J. (2007). Effect of storage, processing and cooking on glucosinolate content of Brassica vegetables. Food and Chemical Toxicology, 45, 216-224.

Son, M. J., Rico, C. W., Nam, S. H., \& Kang, M. Y. (2010). Effect of oryzanol and ferulic acid on the glucose metabolism of mice fed with a high-fat diet. Journal of Food Science, 76(1), H7-H10.

Stahl, W., \& Sies, H. (2005). Bioactivity and protective effects of natural carotenoids. BBA-Molecular Basis of Disease, 1740(2), 101-107.

Stern, J. S., Hirsch, J., Blair, S. N., Foreyt, J. P., Frank, A., \& Kumanyika, S. K. (1995). Weighing the options: criteria for evaluating weight-management programs. The Committee to Develop Criteria for Evaluating the Outcomes of Approaches to Prevent and Treat Obesity. Obesity Research, 3, 591-604.

Strobel, P., Allard, C., Perez-Acle, T., Calderon, R., Aldunate, R., \& Leighton, F. (2005). Myricetin, quercetin and catechin-gallate inhibit glucose uptake in isolated rat adipocytes. Biochemical Journal, 386, 471-8.

Suganuma, M., Okabe, S., Kai, Y., Sueoka, N., Sueoka, E., \& Fujiki, H. (1999). Synergistic effects of (-)-epigallocatechin gallate with (-)-epicatechin, sulindac, or tamoxifen on cancer-preventive activity in the human lung cancer cell line PC-9. Cancer Research, 59, 44-7.

Sun, T., Xu, Z., Wu, C-T., Janes. M., Prinyawiwatkul, W., \& No, H. K. (2007). Antioxidant activities of different colored sweet bell peppers (Capsicum annuum L.). Journal of Food Science, 72, S98-S102.

Takenaka, M., Nanayama, K., Isobe, S., \& Murata, M. (2006). Changes in caffeic acid derivatives in sweetpotato (Ipomoea batatas L.) during cooking and processing. Bioscience, Biotechnology, and Biochemistry, 70, 172-177.

Teow, C. C., Truong, V-D., McFeeters, R. F., Thompson, R. L., Pecota, K. V., \& Yencho, G. C. (2007). Antioxidant activities, phenolic and $\beta$-carotene contents of sweetpotato genotypes with varying flesh colours. Food Chemistry, 103, 829-38.

Tiwari, U., \& Cummins, E. (2011). Factors influencing levels of phytochemicals in selected fruit and vegetables during pre- an post-harvest food processing operations. Food Research International, doi: 10.1016/j.foodres.2011.09.007.

Truong, V-D., McFeeters, R. F., Thompson, R. T., Dean, L. L., \& Shofran, B. (2007). Phenolic acid content and composition in leaves and roots of common commercial sweetpotato (Ipomea batatas L.) cultivars in the United States. Journal of Food Science, 72, C343-C349.

Tsuda, T. (2008). Regulation of adipocyte function by anthocyanins; possibility of preventing the metabolic syndrome. Journal of Agricultural and Food Chemistry, 56(3), 642-6.

Tudela, J. A., Cantos, E., Espan, J. C., Tomas-Barberan, F. A., \& Gil, M. I. (2002). Induction of antioxidant flavonol biosynthesis in fresh-cut potatoes. Effect of domestic cooking. Journal of Agricultural and Food Chemistry, 50, 5925-5931. 
1169

1170

1171

1172

1173

1174

1175

1176

1177

1178

1179

1180

1181

1182

1183

1184

1185

1186

1187

1188

1189

1190

1191

1192

1193

1194

1195

1196

1197

1198

1199

1200

1201

1202

1203

1204

1205

1206

1207

Vallejo, F., Tomas-Barberan, F. A., \& Garcia-Viguera, C. (2002). Glucosinolates and vitamin $\mathrm{C}$ content in edible parts of broccoli florets after domestic cooking. European Food Research and Technology, 215, 310-316.

Van Jaarsveld, P. J., Marais, D. W., Harmse, E., Nestel, P., \& Rodriguez-Amaya, D. B. (2006). Retention of $\beta$-carotene in boiled, mashed orange-fleshed sweetpotatoes. Journal of Food Composition and Analysis, 19, 321-9.

Volden, J., Bengtsson, G. B., \& Wicklund, T. (2009). Glucosinolates, I-ascorbic acid, total phenols, anthocyanins, antioxidant capacities and colour in cauliflower (Brassica oleracea L. ssp. botrytis), effect and long-term freezer strorage. Food Chemistry, 112(4), 967-976.

Wadden, T. A. (1993). Treatment of obesity by moderate and severe caloric restriction. Results of clinical research trials. Annals of Internal Medicine, 119, 688-93.

Wang, M. Y., Tadmor, Q. L., Wu, C. K., Chin, S. A., Garrison, J., \& Simon, J. E. (2003). Characterization and Quantification of Major Steroidal Saponins and Flavonoids in Asparagus Shoots by LC/MS and HPLC Methods. Journal of Agricultural and Food Chemistry, 51, 6132-6136.

Williams, D. J., Critchley, C., Pun, S., Nottingham, S., \& O'Hare, T. J. (2008). Epithiospecifier protein activity in broccoli: the link between terminal alkenyl glucosinolates and sulphoraphane nitrile. Phytochemistry, 69, 2765-2773.

Woo, K. J., \& Kwon, T. K. (2007). Sulphoraphane suppresses lipopoly-saccharideinduced cyclooxygenase-2 (COX-2) expression through the modulation of multiple targets in COX-2 gene promoter. International Immunopharmacology, 7, 1776-1783.

World Health Organization. (1998). Obesity: preventing and managing the global epidemic - report of a WHO consultation on obesity. Geneva, Switzerland.

World Health Organization. (2007). Global strategy on diet, physical activity and health. Geneva, Switzerland.

Yang, J. Y., Della-Fera, M. A., Hausman, D. B., \& Baile, C. A. (2007). Enhancement of ajoene-induced apoptosis by conjugated linoleic acid in 3T3-L1 adipocytes. Apoptosis, 14, 388-397.

Yang, J. Y., Della-Fera, M. A., Nelson-Dooley, C., \& Baile, C. A. (2006). Molecular mechanisms of apoptosis induced by ajoene in 3T3-L1 adipocytes. Obesity, 14, 388-397.

Yun, J. W. (2010). Possible anti-obesity therapeutics from nature - a review. Phytochemistry, 71, 1625-1641. 
1208 (a) Phenolic acids

1209 Hydroxycinnamic acids

1210<smiles>O=C(O)/C=C/c1ccc(O)c(O)c1</smiles>

Caffeic acid $\mathrm{R}=\mathrm{H}$

Chlorogenic acid $\mathrm{R}=$ Quinic acid

1211 Hydroxybenzoic acids

1212<smiles>[R]c1cc(C(=O)O)cc([R])c1[2H]</smiles>

1213 (b) Flavonoids

1214 Flavonols

1215<smiles>[R]c1cc(-c2oc3cc(O)cc(O)c3c(=O)c2O)cc(Br)c1[R]</smiles>

Quercetin $\mathrm{R}_{1}=\mathrm{H} ; \mathrm{R}_{2}=\mathrm{R}_{3}=\mathrm{OH}$

Kaempferol $\mathrm{R}_{1}=\mathrm{R}_{3}=\mathrm{H} ; \mathrm{R}_{2}=\mathrm{OH}$

Myricetin $\mathrm{R}_{1}=\mathrm{R}_{2}=\mathrm{R}_{3}=\mathrm{OH}$

Isorhamnetin $\mathrm{R}_{1}=\mathrm{H} ; \mathrm{R}_{2}=\mathrm{OCH}_{3} ; \mathrm{R}_{3}=$ $\mathrm{OH}$

1216 Flavones<smiles>[R]c1ccc(-c2oc3cc(O)cc(O)c3c(=O)c2O)cc1[R]</smiles>

Luteolin $\mathrm{R}_{1}=\mathrm{R}_{2}=\mathrm{OH}$

Apigenin $\mathrm{R}_{1}=\mathrm{OH} ; \mathrm{R}_{2}=\mathrm{H}$

1219 Figure 1. Phytochemicals with reported anti-obesity effects 
1222 Table 1 Hydroxycinnamic acid content $(\mathrm{mg} / \mathrm{kg})$ of vegetables

1223

\begin{tabular}{lcl}
\hline Vegetable & $\begin{array}{c}\text { Chlorogenic acid+ } \\
\text { Caffeoylquinic acids }\end{array}$ & Reference \\
\hline Carrot & $150-260^{a}$ & Mattila \& Hellstrom, 2007 \\
Globe artichoke & $2930^{a}$ & Ferracane et al. 2008 \\
Lettuce-red leafed-red tissue & $1696^{a}$ & Ferreres et al. 1997 \\
Lettuce-red leafed-green & $570^{a}$ & Ferreres et al. 1997 \\
tissue & & \\
Lettuce-red leafed-midribs & $213^{a}$ & Ferreres et al. 1997 \\
(white tissue) & & \\
Potato-small russet & $133^{a}$ & Friedman, 1997 \\
Potato-large russet & $142^{a}$ & Friedman, 1997 \\
Potato roots & $260^{a}$ & Friedman, 1997 \\
Potato tubers & $170^{a}$ & Friedman, 1997 \\
Sweetpotato-cream fleshed & $31-46^{a}$ & Rautenbach et al. 2010 \\
Sweetpotato-orange fleshed & $190-580^{b}$ & Padda \& Picha, 2008 \\
Sweetpotato-purple fleshed & $1150^{b}$ & Padda \& Picha, 2008 \\
Sweetpotato-white fleshed & $93-910^{b}$ & Padda \& Picha, 2008 \\
Sweetpotato leaves & $4305-4630^{a}$ & Truong et al. 2007 \\
Sweetpotato peel & $585-1050^{a}$ & Truong et al. 2007 \\
Sweetpotato whole root & $80-320^{a}$ & Truong et al. 2007 \\
Sweetpotato periderm & $20-1825^{b}$ & Harrison et al. 2008 \\
Sweetpotato cortex & $1830-12440^{b}$ & Harrison et al. 2008 \\
Sweetpotato stele & $505-12205^{b}$ & Harrison et al. 2008 \\
Sweetpotato leaves-immature & $88500^{b}$ & Padda \& Picha, 2007 \\
Sweetpotato root-small & $10300^{b}$ & Padda \& Picha, 2007 \\
\hline a & &
\end{tabular}


Table 2 Flavonol content ( $\mathrm{mg} / \mathrm{kg}$ fresh weight) of vegetables

\begin{tabular}{|c|c|c|c|c|}
\hline Vegetable & Quercetin & Kaempferol $^{\dagger}$ & Myricetin $^{+}$ & Reference \\
\hline Broccoli & 40 & 40 & & Harnly et al. 2006 \\
\hline Broccoli & $30-37$ & $60-72$ & & Hollman \& Arts, 2000 \\
\hline Capsicum-red & 34 & & & Sun et al. 2007 \\
\hline Capsicum-yellow & 30 & & & Sun et al. 2007 \\
\hline Capsicum-orange & 29 & & & Sun et al. 2007 \\
\hline Capsicum-green & 27 & & & Sun et al. 2007 \\
\hline Kale & $110-120$ & $211-470$ & & Hollman \& Arts, 2000 \\
\hline Kale-red curly & 467 & 480 & & Olsen et al. 2010 \\
\hline $\begin{array}{l}\text { Letttuce-green } \\
\text { leafed }\end{array}$ & $11-147$ & & & Crozier et al. 1997 \\
\hline Lettuce-red leafed & $450-911$ & & & Crozier et al. 1997 \\
\hline $\begin{array}{l}\text { Lettuce-red } \\
\text { leafed-green } \\
\text { tissue }\end{array}$ & 244 & & & Ferreres et al. 1997 \\
\hline Onion-red & 201 & & & Crozier et al. 1997 \\
\hline Onion-red & 334 & 11 & 27 & USDA, 2007 \\
\hline Onion-red & $415-1917$ & & & Slimestad et al. 2007 \\
\hline Onion-inner leaves & 26 & 0.6 & 0.2 & Chu et al. 2000 \\
\hline Onion-outer leaves & 59 & 5 & nd & Chu et al. 2000 \\
\hline Onion-red-dry skin & 1900 & & & Gennaro et al. 2002 \\
\hline $\begin{array}{l}\text { Onion-red-outer } \\
\text { fleshy layer }\end{array}$ & 660 & & & Gennaro et al. 2002 \\
\hline $\begin{array}{l}\text { Onion-red-edible } \\
\text { portion }\end{array}$ & 600 & & & Gennaro et al. 2002 \\
\hline Onion-yellow & -1187 & & & Slimestad et al. 2007 \\
\hline Onion-yellow & 214 & 6 & 0.2 & USDA, 2007 \\
\hline Onion-white & $5-634$ & & & Crozier et al. 1997 \\
\hline $\begin{array}{l}\text { Sweetpotato } \\
\text { leaves-purple }\end{array}$ & 270 & & 156 & Chu et al. 2000 \\
\hline $\begin{array}{l}\text { Sweetpotato } \\
\text { leaves-green }\end{array}$ & & & 39 & Chu et al. 2000 \\
\hline
\end{tabular}


Table 3 Flavone content (expressed as $\mathrm{mg} / \mathrm{kg}$ fresh weight) of vegetables

\begin{tabular}{lccl}
\hline Vegetable & Luteolin $^{+}$ & Apigenin $^{+}$ & Reference \\
\hline Broccoli & 8 & nd & Harnly et al. 2006 \\
Capsicum-green & 21 & nd & Arabbi et al. 2004 \\
Capsicum-green & 2 & & Sun et al. 2007 \\
Capsicum-orange & 7 & & Sun et al. 2007 \\
Capsicum-red & 11 & & Sun et al. 2007 \\
Capsicum-red & $5-11$ & & Hollman \& Arts, 2000 \\
Capsicum-yellow & 9 & nd & Arabbi et al. 2004 \\
Celery & 13 & 46 & Harnly et al. 2006 \\
Celery leaf & 200 & 750 & Hollman \& Arts, 2000 \\
Celery stalk-white & 38 & 97 & Crozier et al. 1997 \\
Celery heart-green & 35 & 191 & Crozier et al. 1997 \\
Celery stalk & $5-20$ & 61 & Hollman \& Arts, 2000 \\
Globe artichoke & 75 & 100 & Azzini et al. 2003 \\
Celery heart-white & 7 & 17 & Hollman \& Arts, 2000 \\
Onions-inner leaves & 0.2 & 0.04 & Chu et al. 2000 \\
Onions-outer leaves & nd & nd & Chu et al. 2000 \\
Parsley & 3 & 119 & Meyer et al. 2006 \\
Sweetpotato leaves-green & nd & 2 & Chu et al. 2000 \\
Sweetpotato leaves-purple & 4 & nd & Chu et al. 2000 \\
\hline
\end{tabular}

${ }^{+}$blank entries indicate component not reported in study nd- not detected 